\title{
İTAKİ Düşme Riski Ölçeği'nin Psikometrik Özelliklerinin Değerlendirilmesi
}

\author{
Veysel Karani BARIŞ*, Seyda SEREN İNTEPELER**, Serap ILERI ${ }^{* * *}$, Hacer RASTGEL****
}

Öz

\begin{abstract}
Giriş: Hasta düşmelerinin önlenebilmesi için ilk olarak hastaların düşme risk faktörlerinin ve bu risk faktörlerine yönelik önleyici girişimlerin belirlenmesi gerekmektedir. Hastaların düşme risk faktörlerinin doğru belirlenebilmesi içinse geçerli ve güvenilir risk değerlendirme aracına ihtiyaç vardır. Amaç: Araştırmanın amacı, İTAKİ Düşme Riski Ölçeği’nin psikometrik özelliklerinin değerlendirilmesidir. Yöntem: Vakakontrol metodolojik tasarıma sahip olan araştırma, bir üniversite ve eğitim araştırma hastanesinde gerçekleştirilmiştir. Vaka ve kontrol grubunda yer alan toplam 605 hastanın bilgilerine hastanelerin bilgi işlem birimlerinden ve hasta dosyalarından ulaşılmıştır. İTAKİ Düşme Riski Ölçeği’nin güvenirliği Cronbach alpha katsayısı ve madde toplam puan korelasyonu, geçerliği ise alıcı işlem karakteristiği (ROC eğrisi), duyarlılık, özgüllük, pozitif ön görü değeri ve negatif öngörü değerleri hesaplanarak değerlendirilmiştir. Bulgular: İTAKİ Düşme Riski Ölçeği'nin Cronbach alpha katsayısı .46 olarak hesaplanmıştır. Gerçekleştirilen madde toplam puan korelasyon analizi sonucunda ölçekte yer alan altı maddenin toplam puan ile istatistiksel olarak anlamlı bir korelasyona sahip olmadığı saptanmıştır. İTAKİ Düşme Riski Ölçeği’nin duyarlılık değeri .91, özgüllük değeri .17, pozitif öngörü değeri .36, negatif öngörü değeri ise .78 olarak hesaplanmıştır. ROC analizi sonucunda ROC Eğrisi Altında Kalan Alan .58 olarak hesaplanmıştır ( $p=.006, \% 95$ Güven Aralığ = .53 - .64). Sonuç: Araştırma kapsamında İTAKI Düşme Riski Ölçeği'nin güvenirliği ve ayırım gücü düşük saptanmıştır. Sonraki araştırmalarda ölçeğin revize edilerek daha geniş bir örneklemde uygulanması önerilir.
\end{abstract}

Anahtar kelimeler: Hasta Düşmesi, Düşme Risk Faktörü, İTAKİ, Psikometrik Özellikler.

\section{Abstract}

Evaluation of Psychometric Properties of ITAKI Fall Risk Scale

Background: In order to prevent patient falls, it is first necessary to determine the fall risk factors and preventive interventions for these factors. To determine the fall risk factors of patients correctly, a valid and reliable risk assessment tool is needed. Objectives: The aim of the research is to evaluate the psychometric properties of the ITAKI Fall Risk Scale. Methods: The research is case-control methodologically designed and conducted at a university and educational research hospital. The information of 605 patients in the case and control groups was accessed from the computing software of the hospitals and patient files. The reliability of the scale was evaluated by calculating the Cronbach alpha coefficient and item total score correlation, and validity was evaluated by ROC curve, sensitivity, specificity, positive predictive value and negative foresight values. Results: Cronbach alpha coefficient of the scale was calculated as .46. It was determined that the six items in the scale did not have a statistically significant correlation with the total score. The sensitivity value of the scale was calculated as .91, specificity value .17, positive prediction value .36 and negative prediction value .78. As a result of the ROC analysis, the Under the Area of ROC Curve was calculated as $.58(p=.006,95 \%$ Confidence Intervals $=.53-.64)$. Conclusion: Reliability and discrimination validity of ITAKI Fall Risk Scale were found low. For future research, it is recommended that the scale is revised and applied in a larger sample.

Key words: Patient Falls, Fall Risk Factor, ITAKI, Psychometric Properties.

Geliş tarihi: 05.05.2020 Kabul tarihi: 08.06.2020

$\mathrm{H}$ astanelerde en sık gerçekleşen tıbbi hatalardan olan hasta düşmeleri hemşirelik bakımı ile ilişkili hataların yaklaşık \%40'ını oluşturmaktadır (1). Düşmelerin büyük bir çoğunluğu herhangi bir yaralanmaya neden olmazken kırıklar, omurga yaralanmaları ve ölümler ile de sonuçlanabilmektedir. Ayrıca düşmeler neden oldukları düşme korkusu gibi sorunlar nedeniyle hastaların mental/ruhsal sağlığını da tehdit etmektedir (2). Ülkemizdeki 28 hastanede yapılan bir araştırmaya göre gerçekleşen 1441 hasta düşmesinin \%61.2'sinde herhangi bir yaralanma görülmezken, \%9.23’ü orta şiddetli ve ciddi yaralanmalar, \%0.97'si ise ölüm ile sonuçlanmıştır (3). Düşmelere bağlı yaralanmalar hastaların bakım ihtiyacının artmasına neden olarak hastanede yatış süresini ve sağlık hizmeti maliyetlerini de artırmaktadır. Literatürde düşmelerin hastanede yatış maliyetini \$3,302.60-\$13,806, hastane yatış süresini ise 7-34 gün artırdığı belirtilmektedir (3-6).

Gerçekleştirilen araştırmalar sonucunda hasta düşmelerinin birçok faktörden etkilenebilen karmaşık bir olay olduğu saptanmıştır (7-10). Düşmelere neden olan bu faktörlerden kaygan zemin, uygun olmayan yatak gibi çevresel faktörleri ortadan kaldırmak mümkündür. Ancak baş dönmesi, güçsüzlük, kronik hastalık gibi hastanın fizyolojik durumundan kaynaklı birçok risk faktörünü ortadan kaldırmak çoğu zaman mümkün olmamaktadır. Bu nedenle risk faktörlerinin erken dönemde saptanması ve her bir risk faktörüne özgü uygulanacak etkili girişimler ile bu risk faktörlerinin düşmelere yol açması engellenmelidir. Düşmeye neden olabilecek risk faktörlerinin erken dönemde saptanabilmesi için ise düşme risk değerlendirme araçlarına gereksinim bulunmaktadır $(11,12)$.

Alan yazındaki hasta düşmelerinin önlenmesi ile ilgili kanıt rehberlerinde ilk uygulanması önerilen ve kanıt düzeyi yüksek olan girişim hastanın düşme riskinin güvenilir bir ölçüm aracı ile değerlendirilmesidir $(13,14)$. Cameron ve arkadaşları (2012) tarafından Cochrane'de yayımlanan rehbere göre hastalarda var olan risk faktörlerine yönelik belirlenen düşme önleyici girişimlerin uygulanması düşme oranlarında yaklaşık \%31 oranında bir azalma sağlamaktadır (15). Ayrıca Chari ve arkadaşları (2013) ise gerçekleştirdikleri araştırmada, düşme risk değerlendirmesi yapılan hastalarda düşmelere bağlı kırıkların risk değerlendirmesi yapılmayan hastalara göre \%40 daha az görüldüğünü saptamıştır (16).

* Arş.Gör. Dokuz Eylül Üniversitesi Hemşirelik Fakültesi Hemşirelikte Yönetim Anabilim Dalı, İnciraltı/İzmir Orcid: https://orcid.org/00000001-5322-4081 e - posta: veyselkaranibaris@gmail.com ** Profesör Doktor, Dokuz Eylül Üniversitesi Hemşirelik Fakültesi Hemşirelikte Yönetim Anabilim Dalı, İnciraltı/İzmir Orcid: https://orcid.org/0000-0001-8615-9765 e - posta: seydaseren@gmail.com *** Uzman Hemşire, Dokuz Eylül Üniversitesi Hastanesi, İnciralt//İzmir Orcid: https://orcid.org/0000-0003-2031-996X e - posta: serapileri@yahoo.com **** Uzman Hemşire, İzmir Sağlık Bilimleri Üniversitesi Tepecik Eğitim ve Araştırma Hastanesi, Konak/İzmir, Orcid: $\underline{7720-9476}$ e - posta: hacer.rastgel@saglik.gov.tr 
Hasta düşmelerinin önlemesinde risk değerlendirmenin başarı sağlayabilmesi için değerlendirme aracının hastalarda var olan riskleri doğru saptayabilmesi ve düşme riski yüksek olan hastaları ayırt edebilmesi beklenmektedir. Dolayısı ile doğru hastaya doğru düşme önleyici girişimi belirleyebilmek için kullanılan düşme risk değerlendirme aracının güvenilir, kullanışlı ve yeterli duyarlık ve özgüllüğe sahip olması gerekmektedir $(11,17)$. Aksi takdirde kullanılan risk değerlendirme aracı uygulanan düşme önleyici programların başarısız olmasına neden olabilmektedir (18).

Alan yazında yetişkin hastalarda uygulanmak üzere geliştirilmiş olan birçok düşme risk değerlendirme aracı (Morse Düşme Riski Ölçeği, Hendrich II Düşme Riski Ölçeği, STRATIFY Düşme Riski Ölçeği vb.) bulunmaktadır (19-21). Ancak bu ölçeklerden herhangi biri hastaların düşme risklerinin değerlendirilmesinde henüz altın standart olarak kabul edilmemiştir. Ölçekler farklı popülasyonlarda farklı sonuçlar vermektedirler (22,23). Ülkemizde ise Sağlık Bakanlığı tarafından yayımlanan Sağlıkta Kalite Standartları - Hastane kapsamında hastaların düşme riski düzeylerinin ulusal veya uluslararası geçerliği olan bir düşme riski ölçeği ile değerlendirilmesi beklenmektedir. Dolayısıyla sağlık kurumlarında yetişkin hastaların düşme risklerinin değerlendirilmesinde yaygın olarak Sağlık Bakanlığı tarafından geliştirilen İTAKİ Düşme Riski Ölçeği kullanılmaktadır (24). İTAKİ Düşme Riski Ölçeği uzun yıllardır ülkemizde kullanılmasına rağmen genel hasta popülasyonunda güvenirlik ve geçerliğinin incelendiği herhangi bir araştırmaya ulaşılamamıştır. Düşme önleyici programların ilk basamağının hasta düşme riskinin değerlendirilmesi olduğu düşünüldüğünde, İTAKİ Düşme Riski Ölçeği'nin psikometrik özelliklerinin değerlendirilmesi ülkemizdeki düşme önleyici programların başarısına katkı sağlayacaktır.

Amaç

Araştırmanın amacı, İTAKİ Düşme Riski Ölçeği’nin psikometrik özelliklerinin değerlendirilmesidir.

Araştırma Sorusu

- İTAKİ Düşme Riski Ölçeği geçerli ve güvenilir bir ölçek midir?

\section{Yöntem}

\section{Araştırmanın Tipi}

Araştırma vaka kontrol metodolojik tasarımda retrospektif bir çalışmadır.

\section{Araştırmanın Yeri ve Zamanı}

Araştırma Mayıs 2019 - Ocak 2020 tarihleri arasında İzmir ilindeki bir üniversite hastanesi ve bir eğitim araştırma hastanesinde gerçekleştirilmiştir. Üniversite hastanesi 1080 yatak kapasitesine sahiptir ve 802 hemşire çalışmaktadır. Eğitim ve araştırma hastanesi ise 910 yatak kapasitesine sahiptir ve 870 hemşire çalışmaktadır. Araştırmanın yürütüldügü hastanelerde, kalite çalışmaları kapsamında düşmeler kalite birimi tarafından düzenli olarak izlenmektedir.
\end{abstract}

\title{
Araştırmanın Evreni ve Örneklemi
}

Araştırmanın gerçekleştirildiği hastanelerde yatarak sağlık hizmeti alan 16 yaş üzeri tüm hastalar araştırmanın hedef popülasyonunu oluşturmaktadır.

\section{Güvenirlik Örnekleminin Belirlenmesi}

Güvenirliğin test edilmesi için araştırmanın yürütüldüğü eğitim ve araştırma hastanesinde araştırmanın yürütüldüğü tarihlerde yatarak sağlık hizmeti alan 16 yaş üstü hastalar araştırmaya dahil edilmiştir. Güvenirlik analizleri için ölçekte yer alan madde sayısının en az 10 katı kadar örnekleme ulaşılması önerilmektedir (25). İTAKİ Düşme Riski Ölçeği'nde toplam 19 madde yer aldığı için en az 190 örnekleme ulaşılması hedeflenmiştir. Araştırma kapsamında veri kayıpları olabileceği öngörüsüyle farklı 17 klinikte yatan toplam 203 hastaya ulaşılmıştır.

Geçerlik Örnekleminin Belirlenmesi

Araştırmada İTAKİ Düşme Riski Ölçeği’nin geçerliğinin değerlendirilmesinde, eşleştirilmiş grupların karşılaştırılması yöntemi kullanılmıştır. Bu kapsamda araştırmanın gerçekleştirildiği hastanelerde 2018 yılı içerisinde düşme deneyimi yaşayan ve bildirimi yapılan hastalar vaka grubu, belirlenen kriterler doğrultusunda vaka grubu hastalar ile eşleştirilen ve hastanede yattığı süre içerisinde düşme deneyimi yaşamayan hastalar ise kontrol grubu olarak belirlenmiştir. Araştırma kapsamında ulaşılması hedeflenen vaka grubu sayısı Flahault ve arkadaşları (2005)'nın yayımlamış olduğu duyarlık ve geçerlik çalışmaları için örneklem hesaplama kriterleri temel alınarak belirlenmiştir (26). Buna göre araştırma kapsamındaki kriterler doğrultusunda (duyarlık ve geçerlik değeri hedefi $=.90, \% 95$ güven aralığındaki en düşük duyarlılık değeri hedefi $=.70$ ) ulaşılması hedeflenen vaka grubu sayısı 41 olarak hesaplanmıştır. Araştırma kapsamında vaka - kontrol eşleştirme oranına 1:2 olarak karar verildiği için hedeflenen en düşük kontrol grubu sayısı ise 82 olarak belirlenmiştir.

Vaka grubu dahil olma kriterleri:

- Hastanın hastanede sağlık hizmeti aldığı süre içerisinde düşme deneyimi yaşamış olması,

- Gerçekleşen düşme olayının yazılı ya da sanal ortamdan bildiriminin yapılmış olması,

Vaka grubu dışlama kriterleri:

- Hastanın bilgilerine (tanısı, hastanede yattı̆̆ı süre içerisinde yapılan işlemler vb.) ulaşılamaması,

- Hastanın belirlenen eşleştirme kriterleri doğrultusunda düşme deneyimi yaşamamış herhangi bir hasta ile eşleştirilememesi.

Kontrol grubu dâhil olma kriterleri:

- Hastanın çalışmanın gerçekleştirildiği hastanelerde yatarak sağlık hizmeti almış olması,

- Eşleştirildiği düşen hasta ile

- Aynı yatış tanısına sahip olması,

- Aynı yaşlarda ( \pm 5$)$ olması,

- Aynı cinsiyette olmasi, 
- Aynı hastanede ve serviste tedavi görmesi ve

- Düşen hasta ile yatış tarihleri arasındaki zaman farkının bir yıldan az olması. (Örneğin vaka grubundaki hasta 2018 yılında sağlık hizmeti almış ise kontrol grubundaki hasta, 2017-2019 tarihleri arasında sağlık hizmeti alan hastalar arasından seçilmiştir.)

Kontrol grubu dışlama kriterleri:

- Hastanın hastanede yattığı süre içerisinde düşme olayını deneyimlemesi,

- Hastanın bilgilerine (tanısı, hastanede yattığı süre içerisinde yapılan işlemler vb.) ulaşılamaması.

Araştırma kapsamında belirlenen kriterler doğrultusunda 138 vaka grubu hastası 264 kontrol grubu hastası ile eşleştirilmiştir. Bu doğrultuda İTAKİ Düşme Riski Ölçeği’nin geçerlik analizleri iki farklı hastanenin 21 farklı kliniğinde yatarak sağlık hizmeti alan 402 hastaya ait veriler ile gerçekleştirilmiştir.

\section{Veri Toplama Araçlart}

Araştırma kapsamında, hastaların sosyo-demografik ve düşme özelliklerini tanımlamaya yönelik sosyo-demografik ve düşme bilgileri veri toplama formu, hastaların düşme risklerinin değerlendirilmesinde ise İTAKİ Düşme Riski Ölçeği kullanılmıştır.

Sosyo-demografik ve Düşme Bilgileri Veri Toplama Formu: Araştırmacılar tarafından oluşturulan formda hastanın yaşı, cinsiyeti, sağlık hizmeti aldığı hastane ve klinik, yatış tanısı, yatış ve taburculuk tarihi, İTAKİ Düşme Riski Ölçeği puanı, düşme gerçekleşme durumu ile ilgili 10 adet soru yer almaktadır.

ITAKI Düşme Riski Ölçeği: Ölçek, Sağlık Bakanlı̆̆ı tarafından geliştirilmiş olup hasta düşmelerine neden olabilecek toplam 19 risk faktöründen oluşmaktadır (24). Risk faktörleri majör ve minör olarak kategorize edilerek, minör risk faktörlerine birer puan, majör risk faktörlerine ise beşer puan verilmiştir. Toplam 11 adet minör, sekiz adet majör risk faktörü bulunmaktadır. Risk faktörlerinin değerlendirilmesi sonucu elde edilen toplam puan üzerinden düşük ve yüksek olmak üzere iki risk düzeyi belirlenmiştir. Eğer toplam puan beşin altında ise hastanın düşme riski düşük, beş ve üzeri ise hastanın düşme riski yüksek kabul edilmektedir.

\section{Verilerin Toplanmast}

Araştırma kapsamında tüm veriler araştırmacılar tarafından toplanmıştır. Düşme olay bildirimlerine üniversite hastanesinde kalite biriminde yer alan yazılı bildirim formlarından, eğitim araştırma hastanesinde ise hasta bilgi sisteminden ulaşılmıştır. Vaka ve kontrol grubunda yer alan hastalara ait bilgilere ise üniversite hastanesinde hastane bilgi yönetim sistemi ve hastaların arşiv dosyalarından ulaşılırken, eğitim araştırma hastanesinde bilgi yönetim sisteminden ulaşılmıştır. Hastaların İTAKİ Düşme Riski Ölçek puanı olarak hemşirelerin kayıt altına almış olduğu değerlendirmeler temel alınmıştır.

\section{Verilerin Değerlendirilmesi}

Araştırma kapsamında İTAKİ Düşme Riski Ölçeği’nin güvenirliğinin değerlendirilmesinde iç tutarlık yaklaşımlarından Cronbach alpha katsayısı hesaplanmıştır. Madde toplam puan korelasyon analizi için Pearson korelasyon analizi kullanılmıştır. Ölçeğin geçerliğinin değerlendirilmesinde ise alıcı işlem karakteristiği (ROC eğrisi), Duyarlılık, Özgüllük, Pozitif Ön Görü Değeri ve Negatif Öngörü değerleri hesaplanmıştır. Gerçeklik analizi için kullanılan kavramlara ait formüller Şekil 1.'de yer almaktadır. Ayrıca risk grubuna göre düşme oranlarının karşılaştırılmasında ki kare analizi, düşen ve düşmeyen hastaların İTAKİ ölçek puanlarının karşılaştırılmasında ise bağımsız gruplarda t testi kullanılmıştır.

\begin{tabular}{|c|c|c|c|c|}
\hline & & \multicolumn{2}{|c|}{$\begin{array}{c}\text { Düssme Riski } \\
\text { Durumu }\end{array}$} & \\
\hline & & $\begin{array}{l}\text { Yüksek Risk } \\
\text { (İTAKİ } \geq 5 \text { ) }\end{array}$ & $\begin{array}{l}\text { Düşük Risk } \\
(\text { İTAKİ < 5) }\end{array}$ & \\
\hline \multirow{2}{*}{$\begin{array}{l}\text { Düssme } \\
\text { Durumu }\end{array}$} & Düşme Var & $\begin{array}{l}\text { Gerçek Pozitif } \\
\text { (GP) }\end{array}$ & $\begin{array}{l}\text { Yanlış Negatif } \\
\text { (YN) }\end{array}$ & Duyarlılık $=\frac{G P}{G P+Y N}$ \\
\hline & Düssme Yok & $\begin{array}{l}\text { Yanlıș Pozitif } \\
\text { (YP) }\end{array}$ & $\begin{array}{l}\text { Doğru Negatif } \\
\text { (DN) }\end{array}$ & Özgüllük $=\frac{D N}{Y P+D N}$ \\
\hline & & $\mathrm{PÖD}=\frac{G P}{G P+Y P}$ & $\mathrm{NÖD}=\frac{D N}{Y N+D N}$ & \\
\hline
\end{tabular}

PÖD: Pozitif Öngörü Değeri NÖD: Negatif Öngörü Değeri

Jung H, Park HA. Testing the predictive validity of the Hendrich II fall risk model, Western Journal of Nursing Research, 2018;40(12), 1785-1799 (27).

\section{Sekil 1. Gerçeklik Analizi Kavramları Formülleri}

\section{Araştırmanın Etik Yönü}

Araştırma kapsamında İTAKİ Düşme Riski Ölçeği'nin geçerlik ve güvenirliğinin test edilebilmesi için bakanlığa ait ölçek olması nedeniyle Sağlık Bakanlığı'ndan izin (Sayı: 26325996 Tarih: 19/11/2018) alınmıştır. Ayrıca araştırmanın gerçekleştirilebilmesi için üniversite hastanesinden (Sayı: 72292585-10.99-E.37134 Tarih: 10/05/2019) ve Sağlık Bakanlığı (Sayı: 26325996 Tarih: 19/11/2018)'ndan kurum izni alınmıştır. Etik açıdan ise bir üniversitenin girişimsel olmayan araştırmalar etik kurulundan onay alınmıştır (Karar No: 2019/17-39 Tarih: 17/07/2019). Makalenin tüm aşamalarında araştırma ve yayın etiğine uyulmuştur. 


\section{Bulgular}

Araştırma kapsamında güvenirlik ve geçerlik analizleri farklı örneklemlerden elde edilen veriler kullanılarak gerçekleştirilmiştir. $\mathrm{Bu}$ nedenle güvenirlik ve geçerlik örneklemlerine ait özellikler ayrı olarak sunulmuştur. Araştırmanın örneklem grubuna ait bilgiler Tablo 1.'de yer almaktadır.

Tablo 1. Araştırma Örneklemi Tanımlayıcı Bilgileri

\begin{tabular}{|c|c|c|c|c|c|c|}
\hline \multirow[t]{2}{*}{ Yaş } & \multicolumn{2}{|c|}{$\begin{array}{c}\text { Güvenirlik Grubu } \\
61.5 \pm 15.5\end{array}$} & \multicolumn{2}{|c|}{$\begin{array}{l}\text { Vaka Grubu } \\
64.52 \pm 17.38\end{array}$} & \multicolumn{2}{|c|}{$\begin{array}{c}\text { Kontrol Grubu } \\
63.84 \pm 17.89\end{array}$} \\
\hline & $\mathbf{n}$ & $\%$ & $\mathbf{n}$ & $\%$ & $\mathbf{n}$ & $\%$ \\
\hline \multicolumn{7}{|l|}{ Cinsiyet } \\
\hline Kadın & 91 & 44.4 & 60 & 43.5 & 116 & 43.9 \\
\hline Erkek & 114 & 55.6 & 78 & 56.5 & 148 & 56.1 \\
\hline \multicolumn{7}{|l|}{ Hastane } \\
\hline Üniversite & - & - & 121 & 87.7 & 230 & 87.1 \\
\hline $\begin{array}{c}\text { Eğitim Araştırma } \\
\text { Birim }\end{array}$ & 205 & 100 & 17 & 12.3 & 34 & 12.9 \\
\hline Dahili Birimler & 55 & 26.8 & 95 & 68.8 & 181 & 68.6 \\
\hline Cerrahi Birimler & 58 & 28.3 & 42 & 30.4 & 81 & 30.6 \\
\hline Dahili Yoğun Bakım & 60 & 29.3 & 1 & 0.8 & 2 & 0.8 \\
\hline Cerrahi Yoğun Bakım & 32 & 15.7 & - & - & - & - \\
\hline Toplam & 205 & 100 & 138 & 100 & 264 & 100 \\
\hline
\end{tabular}

Güvenirlik örnekleminde yaş ortalaması $61.5 \pm 15.5$ örneklemin \%55.6 (114)’sı erkek, \%44.4 (91)’ü kadın hastalardır. Hastaların tamamı eğitim araştırma hastanesinde yatarak sağlık hizmeti almakta olup \%26.8 (55)'i dâhili birimler, \%28.3 (58)'ü cerrahi birimler, \%29.3 (60)'ü dahili yoğun bakımlar ve \%15.7 (32)'si cerrahi yoğun bakımlarda yatan hastalardan oluşmaktadır. Geçerlik analizleri kapsamında vaka grubu örnekleminin yaş ortalaması $64.52 \pm 17.38$, hastanede yatış süresi ortalaması ise $21.94 \pm 17.36$ 'dır. Hastaların \%56.5 (78)'i erkek, \%43,5 (60)'i ise kadındır. Hastaların \%87.7 (121)'si üniversite hastanesinde, \%12.3 (17)'ü eğitim araştırma hastanesinde ise yatarak sağlık hizmeti almakta olup \%68.8 (95)'i dahili birimler, \%30.4 (42)'ü cerrahi birimler ve \%0.8 (1)'i dahili yoğun bakımda yatan hastalardan oluşmaktadır. Hastaların \%52.2 (70)’si hastaneye yatışından sonraki ilk altı gün içerisinde düşmüştür. Kontrol grubundaki hastaların yaş ortalaması $63.84 \pm 17.89$, hastanede ortalama yatış süresi ise $10.88 \pm 10.65$ 'tir. Kontrol grubunun \%56.1 (148)'i erkek, \%43.9 (116)'u kadın hastalardan oluşmaktadır. Hastaların \%12.9 (34)'u eğitim araştırma hastanesinde, \%87.1 (230)'i ise üniversite hastanesinde yatarak sağlık hizmeti almakta olup \%68.6 (181)'s1 dahili birimler, \%30.6 (81)'s1 cerrahi birimler ve \%0.8 (2)'i dahili yoğun bakımda yatan hastalardan oluşmaktadır.

\section{Güvenirlik İle İlgili Bulgular}

Güvenirlik analizleri kapsamında İTAKİ Düşme Riski Ölçeği’nin Cronbach alpha katsayısı .46 olarak hesaplanmıştır. Gerçekleştirilen madde toplam puan korelasyon analizi sonucuna göre ise; "Son 1 ay içerisinde düşme öyküsü var $(r=-.06$, $p=$ .937)", "Görme durumu zayıf $(\mathrm{r}=-.08, \mathrm{p}=.214)$ ", "Hastaya bağlı 3’ün altında bakım ekipmanı var $(\mathrm{r}=-.07, \mathrm{p}=.917)$ ”, "Yatak korkulukları bulunmuyor/çalışmıyor $(\mathrm{r}=-.11, \mathrm{p}=.111)$ ", "Yürüme alanlarında fiziksel engel(ler) var $(\mathrm{r}=.12, \mathrm{p}=.870$. .", "Baş dönmesi var $(\mathrm{r}=.13, \mathrm{p}=.052)$ " madde puanlarının ölçek toplam puanı ile istatistiksel olarak anlamlı bir korelasyona sahip olmadığı saptanmıştır. Toplam puan ile istatistiksel olarak anlamlı bir korelasyona sahip maddelerin korelasyon katsayıları ise .17 ile .68 arasındadır. Korelasyon katsayısı .20’nin altında olan maddeler "Ayakta/yürürken fiziksel desteğe (yürüteç, koltuk değneği, kişi desteği vb.) ihtiyacı var $(\mathrm{r}=.17, \mathrm{p}=.014)$ " ve "Ortostatik hipotansiyonu var $(\mathrm{r}=.19, \mathrm{p}=.006)$ " maddeleridir.

Geçerlik İle İlgili Bulgular

Hastaların risk grubuna göre düşme oranları ile ilgili bilgiler Tablo 2.'de sunulmuştur.

Tablo 2. Kesme Noktası 5 Puan'a Göre Hastaların Düşme Riski Durumu İle Düşme Durumlarının Karşılaştırılması

\begin{tabular}{|c|c|c|c|c|c|c|c|c|}
\hline \multicolumn{9}{|c|}{ DÜŞME DURUMU } \\
\hline \multirow[t]{2}{*}{$\begin{array}{c}\text { ÖLÇEGE GÖRE } \\
\text { DÜŞME RİSKİ }\end{array}$} & \multicolumn{2}{|c|}{ Düştü } & \multicolumn{2}{|c|}{ Düşmedi } & \multicolumn{2}{|c|}{ Toplam } & \multirow[t]{2}{*}{$\mathbf{x}^{2}$} & \multirow{2}{*}{$\mathbf{p}$} \\
\hline & $\mathbf{n}$ & $\%$ & $\mathbf{n}$ & $\%$ & $\mathbf{n}$ & $\%$ & & \\
\hline Yüksek & 125 & 36.4 & 218 & 63.6 & 343 & 100 & \multirow{2}{*}{4.636} & \multirow{2}{*}{.031} \\
\hline Düşük & 13 & 22 & 46 & 78 & 59 & 100 & & \\
\hline Toplam & 138 & 34.32 & 264 & 65.68 & 402 & 100 & & \\
\hline
\end{tabular}

Sağlık Bakanlığı tarafından belirlenen kesme noktası puanına (5 puan) göre İTAKİ Düşme Riski Ölçeği’nin duyarlılık değeri .91, özgüllük değeri .17, pozitif öngörü değeri .36, negatif öngörü değeri ise .78 olarak hesaplanmıştır. Buna göre geçerlik 
örneklemindeki 402 hastanın \%85.32 (343)'si yüksek riskli, \%14.68 (59)'i düşük riskli olarak belirlenmiştir. Yüksek riskli olarak belirlenen 343 hastanın \%36.4 (125)'ü düşme deneyimi yaşarken, düşük riskli olarak belirlenen 59 hastanın \%22 (13)'si düşme deneyimi yaşamıştır. Yüksek riskli olarak belirlenen hastalar ile düşük riskli olarak belirlenen hastaların düşme oranları arasındaki fark istatistiksel olarak anlamlıdır $\left(\mathrm{x}^{2}=4.636, \mathrm{p}=.031\right)$.

Tablo 3. Düş̧en Hastalar İle Düş̧meyen Hastaların ITAKI Ölçek Puan Ortalamalarının Karşılaştırılması

\begin{tabular}{|c|c|c|c|c|c|c|}
\hline Hasta Grubu & $\begin{array}{l}\text { Hasta } \\
\text { sayısı }\end{array}$ & $\begin{array}{c}\text { ITTAKİ Ölçek Puanı } \\
\text { Ortalamaları }\end{array}$ & $\begin{array}{l}\text { Standart } \\
\text { Sapma }\end{array}$ & Standart Hata & $\mathbf{t}$ & $\mathbf{p}$ \\
\hline $\begin{array}{l}\text { Vaka grubu } \\
\text { (düşen hasta) }\end{array}$ & 138 & 10.75 & 5.25 & 0.44 & 2.204 & .029 \\
\hline $\begin{array}{l}\text { Kontrol grubu } \\
\text { (düşmeyen hasta) }\end{array}$ & 264 & 9.14 & 5.40 & 0.33 & & \\
\hline
\end{tabular}

Düşen ve düşmeyen hastaların ölçek puan ortalamaları ile ilgili bilgiler Tablo 3.'de yer almaktadır. Düşen ve düşmeyen hastaların İTAKİ Düşme Riski Ölçeği puan ortalamaları karşılaştırıldığında düşen hastaların puan ortalaması $10.75 \pm 5.25$, düşmeyen hastaların puan ortalaması ise $9.14 \pm 5.40$ 'tır ve aradaki fark istatistiksel olarak anlamlıdır $(\mathrm{t}=2.204, \mathrm{p}=.029)$. Araştırma kapsamında ölçeğin ayırım gücünü değerlendirebilmek için gerçekleştirilen ROC analizi sonucunda ROC Eğrisi Altında Kalan Alan .58 olarak hesaplanmıştır (Grafik 1., p = .006, \%95 Güven Aralığı = .53 - .64).

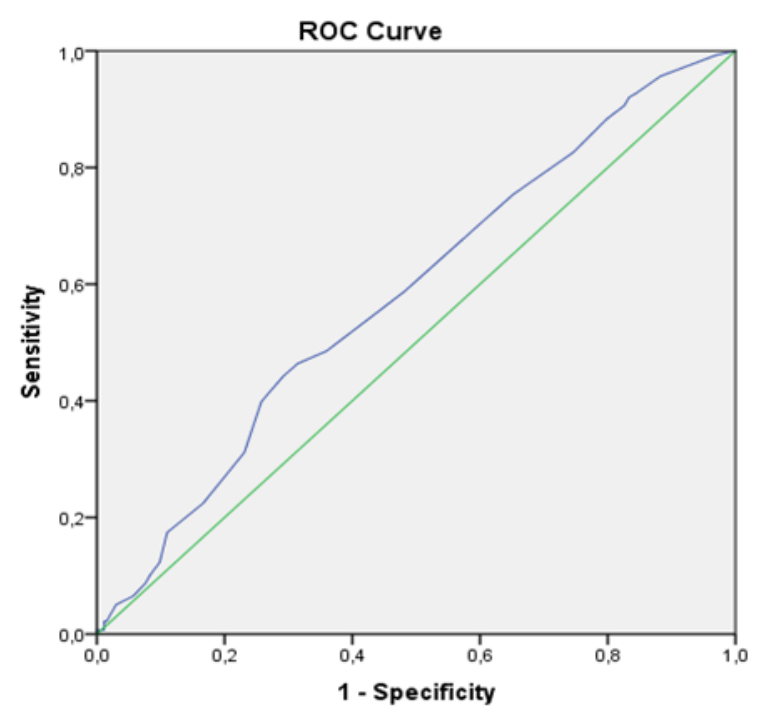

\section{Grafik 1. ROC Ĕgrisi}

Gerçekleştirilen ROC analizi sonucunda elde edilen farklı kesme noktalarına göre İTAKİ Düşme Riski Ölçeği duyarlılık ve özgüllük değerleri Tablo 4.'te sunulmuştur. 
Tablo 4. İTAKİ Ölçeği Farklı Kesme Noktalarına Göre Duyarlılık ve Özgüllük Değerleri

\begin{tabular}{ccc}
\hline Ölçek Kesme Puanı & Duyarlılı & Özgüllük \\
\hline 0.5 & .99 & .03 \\
1.5 & .95 & .11 \\
2.5 & .92 & .15 \\
3.5 & .92 & .16 \\
4.5 & .90 & .17 \\
5.5 & .88 & .20 \\
6.5 & .82 & .25 \\
7.5 & .75 & .34 \\
8.5 & .58 & .51 \\
9.5 & .48 & .64 \\
10.5 & .46 & .68 \\
11.5 & .44 & .70 \\
12.5 & .39 & .74 \\
13.5 & .31 & .76 \\
14.5 & .22 & .83 \\
15.5 & .17 & .89 \\
16.5 & .12 & .90 \\
17.5 & .10 & .91 \\
18.5 & .08 & .92 \\
19.5 & .06 & .94 \\
20.5 & .05 & .97 \\
21.5 & .02 & .98 \\
22.5 & .02 & .98 \\
23.5 & .00 & .98 \\
25.5 & .00 & .00 \\
\hline
\end{tabular}

Buna göre en uygun kesme noktası değerinin 7.5 olduğuna karar verilmiştir. Belirlenen yeni kesme noktasına göre ölçeğin duyarlılık değeri .75 , özgüllük değeri .35 , pozitif öngörü değeri .38 , negatif öngörü değeri ise .73 olarak hesaplanmıştır.

\section{Tartışma}

Gerçekleştirilen güvenirlik analizleri kapsamında İTAKİ Düşme Riski Ölçeği’nin Cronbach alpha katsayısı .46 olarak hesaplanmıştır. Ölçeğin güvenirliği için en önemli göstergelerden olan Cronbach alpha katsayısının .40 'dan küçük olması "ölçeğin güvenilir olmadığını", .40 - .59 arasında olması "düşük güvenirlikte" olduğunu, .60 - .79 arasında olması "oldukça güvenir" olduğunu, .80 - 1.00 arasında olması ise ölçeğin "yüksek derecede güvenilir" olduğunu göstermektedir (28). Bu doğrultuda araştırmadan elde edilen sonuç İTAKİ Düşme Riski Ölçeği’nin güvenirliğinin düşük olduğunu göstermektedir. İTAKİ'nin geçerlik ve güvenirliği ile ilgili doğrudan yapılan başka araştırma sonucuna ulaşılamamakla birlikte alan yazında gerçekleştirilen birçok araştırmada düşme riski ölçeklerinin Cronbach alpha katsayıları düşük bulunmuştur (29-31). Ölçeğin güvenirliğinin düşük çıkmasına maddelerin birbirinden bağımsız olması, likert tipi bir ölçek olmaması ve maddelerin puan yükleri arasındaki farklılıkların yol açtığı düşünülebilir.

Gerçekleştirilen madde toplam puan korelasyon analizine göre ise ölçekte yer alan altı maddenin toplam puan ile istatistiksel olarak anlamlı bir korelasyona sahip olmadığı, iki maddenin korelasyon katsayısının ise kabul edilebilir sınır olarak belirlenen .20 'nin altında olduğu saptanmıştır. Ölçek çalışmalarında madde toplam puan korelasyon katsayısının yüksek olması maddenin ölçülen teorik yapıya uygun olduğunu göstermektedir. Bununla birlikte korelasyon katsayıs1 .20'den düşük olan maddelerin ölçekten çıkarılması veya revize edilmesi önerilmektedir $(28,32,33)$. Elde edilen sonuç bu maddelerin teorik yapı ile uyumsuz olduğunu destekler niteliktedir. Ancak gerçekleştirilen birçok araştırmada bu maddeler ile temsil edilen faktörlerin hasta düşmelerine neden olduğu saptanmıştır $(8-10,34)$. Bu doğrultuda ilgili maddelerin ölçekten çıkarılması veya revizyonu açısından detaylı bir çalışmaya gereksinim bulunmaktadır.

Araştırma kapsamında İTAKİ Düşme Riski Ölçeği'nin geçerliği duyarlılık, özgüllük, pozitif öngörü değeri, negatif öngörü değeri ve ROC eğrisi ile değerlendirilmiştir. Duyarlılık ölçüm aracının düşme riski yüksek olan hastaları doğru olarak belirleyebilme yeteneğidir (35). Araştırma kapsamında daha önceden belirlenen kesme noktası 5 puana göre İTAKİ'nin duyarlılığı yüksek bulunmuştur (.91). Bu sonuç İTAKİ Düşme Riski Ölçeği’nin düşme riski yüksek olan hastaları belirleyebilme yeteneğinin yüksek olduğunu göstermektedir. Ancak ölçeğin düşme riski düşük olan hastaları doğru olarak belirleyebilme yeteneğini ifade eden özgüllük değeri oldukça düşük (.17) saptanmıştır. Alan yazında duyarlılık ile özgüllük değerleri arasında ters ilişki olduğu belirtilmektedir (36). Dolayısıyla kesme noktası değerinin düşük olması birçok hastanın riskli olarak değerlendirilmesine yol açarak duyarlılık değerinin artmasına, özgüllük değerinin de azalmasına neden olduğu düşünülebilir (11, 37). Aynı zamanda bu durum pozitif öngörü değerinin negatif öngörü değerinden düşük olarak hesaplanmasının da nedeni olarak gösterilebilir. Ölçeğin özgülllük değerinin düşük olması düşme riski düşük olan hastaların yüksek olarak sınıflandırılmasına neden olarak düşme önleyici girişimler ile ilgili kaynağın gerçekten ihtiyacı olan hastalar için kullanılamamasına yol açmaktadır. Özellikle iş gücü ve malzeme gibi birçok kaynağın oldukça sınırlı olduğu sağlık hizmetleri sunumunda kaynakların etkin olarak 
kullanılması büyük önem arz etmektedir. Bununla birlikte İTAKİnin düşme riski düşük olan hastaları yüksek olarak saptaması sağlık çalışanlarının risk değerlendirme aracına olan güveninin azalmasına neden olmaktadır (37, 38). Bu durum düşme riski değerlendirme aracının etkili olarak kullanılmamasına neden olarak önleyici programların başarısız olmasına yol açabilecektir.

Araştırma kapsamında gerçekleştirilen ROC analizi sonucunda ROC eğrisi altında kalan alan (area under the ROC curve - AUC) .58 olarak hesaplanmıştır. Ölçeğin risk gruplarını ayırım gücünün en önemli göstergelerinden olan AUC değerinin .50 .70 arasında olması ayırım gücünün "yetersiz", .71 - .80 arasında olması "kabul edilebilir”, .81 - .90 arası "çok iyi”, .91 - 1.00 arası ise "mükemmel” olduğunu ifade etmektedir (39). Bu bilgiler 1şığında İTAKİ Düşme Riski Ölçeği’nin riskli gruplar ayırım gücünün yetersiz olduğu söylenebilir. Gerçekleştirilen ROC analizi ile birlikte İTAKİ Düşme Riski Ölçeği’nin farklı kesim noktalarındaki duyarlık ve özgüllük değerleri de hesaplanmıştır. Bu doğrultuda alan yazında da önerildiği üzere duyarlık (.75) ve özgüllük (.35) değerlerinin daha dengeli olduğu 7.5 puanın ölçeğin kesme noktası olarak kullanılması önerilebilir (29, 37). Pozitif öngörü değeri ve negatif öngörü değerleri 5 ve 7.5 kesme puanlarına göre çok büyük farklılık göstermemektedir.

\section{Kisıtlılıklar}

Araştırma kapsamında sadece olay bildirimi yapılan hasta düşmeleri analize dâhil edilmiştir. Dolayısıyla gerçekleşen tüm hasta düşmelerinin bildiriminin yapıldığı ile ilgili kesin bir bilgi bulunmamaktadır. Gerçekleşen düşmelerin büyük çoğunun bildirilmediği de göz önüne alınırsa bu durum araştırmada elde edilen sonuçların güvenirliği açısından sınırlılık oluşturabilir (4042). Buna ek olarak araştırma sadece bir üniversite ve eğitim araştırma hastanesinde gerçekleştirilmiştir. Ülkemizde şehir hastaneleri, devlet hastaneleri ve özel hastanelerde sunulan sağlık hizmetinin boyutu da değerlendirildiğinde, bu durum araştırma sonuçlarının genellenebilirliği açısından sınırlılık oluşturabilir.

\section{Sonuçların Uygulamada Kullanımı}

Araştırma kapsamında İTAKİ Düşme Riski Ölçeği’nin klinik uygulama için yeterli güvenirlik ve ayırım gücüne sahip olmadığı saptanmıştır. Mevcut durum göz önüne alındığında ölçeğin kullanımı, risk değerlendirmesinin doğru yapılamama olasılığını düşündürmektedir. Dolayısıyla risklere göre gerçekleştirilecek düşme önleyici uygulamaların yetersizliği ile düşük riskli hastaların düşme olasılığı artabilecektir. Araştırmadan elde edilen sonuçların uygulamada etkili olarak kullanılabilmesi açısından, sonraki araştırmalarda İTAKİ Düşme Riski Ölçeği’nin maddeler ve puanlama bazında revize edilerek daha geniş bir örneklemde güvenirlik ve geçerliğinin değerlendirilmesi önerilebilir. Yeni oluşturulacak maddeler ve puanlama ile doğru bir değerlendirme yapılabilecek, düşme önleyici uygulamaların da etkinliği artabilecektir.

\section{Bilgilendirme}

Yazarların araştırmaya katkı oranı beyanları şu şekildedir; araştırmanın konusu ve metodolojisinin belirlenmesi ŞSİ, VKB; verilerin toplanması ve işlenmesi VKB, Sİ, HR; verilerin analizi ve yorumlanması ŞSİ, VKB; makalenin yazılması VKB, ŞSİ, SI, HR. Araştırma için herhangi bir firmadan veya projeden fon desteği alınmamış ve araştırmanın bütçesi araştırmacılar tarafından karşılanmıştır. Araştırmacılar arasında herhangi bir çıkar çatışması bulunmamaktadır. Araştırma ile ilgili bir üniversitenin girişimsel olmayan araştırmalar etik kurulundan onay alınmıştır (Karar No: 2019/17-39 Tarih: 17/07/2019).

\section{Kaynaklar}

1. D’Amour D, Dubois CA, Tchouaket E, Clarke S, Blais R. The occurrence of adverse events potentially attributable to nursing care in medical units: cross sectional record review. Int J Nurs Stud. 2014;51(6):882-891.

2. Schoene D, Heller C, Aung YN, Sieber CC, Kemmler W, Freiberger E. A systematic review on the influence of fear of falling on quality of life in older people: is there a role for falls?, Clin Interv Aging, 2019;14:701-719.

3. Baris VK, Seren Intepeler S, Yeginboy EY. The cost of serious patient fall-related injuries at hospitals in Turkey: A matched casecontrol study. Clin Nurs Res. 2018;27(2):162-179.

4. Wong CA, Recktenwald AJ, Jones ML, Waterman BM, Bollini ML, Dunagan WC. The cost of serious fall-related injuries at three Midwestern hospitals. Jt Comm J Qual Patient Saf. 2011;37:81-87.

5. Zecevic AA, Chesworth BM, Zaric GS, Huang Q, Salmon A, McAuslan D et. al. Estimating the cost of serious injurious falls in a Canadian acute care hospital. Can J Aging 2012;31:139-147.

6. Dunne TJ, Gaboury I, Ashe MC. Falls in hospital increase length of stay regardless of degree of harm. J Eval Clin Pract. 2014;20:396-400.

7. Baris VK, Seren Intepeler S. Views of key stakeholders on the causes of patient falls and prevention interventions: A qualitative study using the international classification of functioning, disability and health, J Clin Nurs. 2019;28:615-628.

8. Deandrea S, Bravi F, Turati F, Lucenteforte E, Vecchia CL, Negri E. Risk factors for falls in older people in nursing homes and hospitals. A systematic review and meta-analysis, Arch Gerontol Geriatr. 2013;56:407-415.

9. O'Neil CA, Krauss J, Bettale J, PharmD K, Costantinou E, Dunagan C et. al. Medications and patient characteristics associated with falling in the hospital, J Patient Saf. 2018;14(1):27-33.

10. Moe K, Brockopp D, McCowan D, Merritt S, Hall B. Major predictors of inpatient falls a multisite study, The Journal of Nursing Administration 2015;45(10):498-502.

11. Poe SS, Dawson PB, Cvach M, Burnett M, Kumble S, Lewis M et. al. The Johns Hopkins Fall Risk Assessment Tool a study of reliability and validity, J Nurs Care Qual. 2018;33(1):10-19.

12. Kim EA, Mordiffi SZ, Bee WH, Devi K, Evans D. Evaluation of three fall-risk assessment tools in an acute care setting. J Adv Nurs 2007;60(4):427-435.

13. Degelau J, Belz M, Bungum L, Flavin PL, Harper C, Leys K et. al. Prevention of falls (acute care). Institute for Clinical Systems Improvement. April 2012.

14. Registered Nurses' Association of Ontario -RNAO- Preventing falls and reducing injury from falls. 4th ed. Registered Nurses’ Association of Ontario; 2017. 
15. Cameron ID, Gillespie LD, Robertson MC, Murray GR, Hill KD, Cumming RG et al. Interventions for preventing falls in older people in care facilities and hospitals. Cochrane Database Syst. Rev. 2012;12, CD005465.

16. Chari S, McRae P, Varghese P, Ferrar K, Haines TP. Predictors of fracture from falls reported in hospital and residential care facilities: a cross-sectional study. BMJ Open 2013;3(8):e002948.

17. Petitpierre NJ, Trombetti A, Carroll I, Michel JP, Herrmann FR. The FIM instrument to identify patients at risk of falling in geriatric wards: a 10-year retrospective study. Age Ageing 2010;39(3):326-331.

18. Ivziku D, Matarese M, Pedone C. Predictive validity of the Hendrich fall risk model II in an acute geriatric unit. Int J Nurs Stud. 2011;48(4):468-474.

19. Morse JM, Morse RM, Tylko SJ. Development of a scale to identify the fall-prone patient. Can J Aging 1989;8:366-371.

20. Hendrich A, Nyhuis A, Kippenbrock T, Soja ME. Hospital falls: developing of a predictive model for clinical practice. Appl Nurs Res 1995;8:129-139.

21. Oliver D, Britton M, Seed P, Martin FC, Hopper AH. Development and evaluation of evidence based risk assessment tool (STRATIFY) to predict which elderly inpatients will fall: case-control and cohort studies. BMJ. 1997;315(7115):10491053.

22. Chapman J, Bachand D, Hyrkäs K. Testing the sensitivity, specificity and feasibility of four falls risk assessment tools in a clinical setting. J Nurs Manag. 2011;19(1):133-142.

23. Park SH. Tools for assessing fall risk in the elderly: a systematic review and meta-analysis. Aging Clin Exp Res. 2018;30(1):1-16.

24. Sağlık Bakanlığg, Sağlıkta Kalite Standartları - Hastane (Versiyon 5, Revizyon-01), Sağlık Hizmetleri Genel Müdürlüğü Sağlıkta Kalite ve Akreditasyon Daire Başkanlığı, 2016, Ankara.

25. Tabachnick BG, Fidell LS. Using multivariate statistics. 6th ed. Pearson; 2013.

26. Flahault A, Cadilhac M, Thomas G. Sample size calculation should be performed for design accuracy in diagnostic test studies. J Clin Epidemiol. 2005;58(8):859-862.

27. Jung H, Park HA. Testing the predictive validity of the Hendrich II Fall Risk Model. Western Journal of Nursing Research 2018;40(12):1785-1799.

28. Akgül A. Tıbbi Araştırmalarda İstatistiksel Analiz Teknikleri ‘SPSS Uygulamaları'. 3. Basım, Emek Ofset; 2005 ; $180-396$.

29. Chow SK, Lai CK, Wong TK, Suen LK, Kong SK, Chan CK et al. (Evaluation of the Morse Fall Scale: applicability in Chinese hospital populations. Int J Nurs Stud. 2007;44(4):556-565.

30. Yılmaz Demir N, Seren İntepeler Ş. Morse düşme ölçeğinin Türkçe’ye uyarlanması ve duyarlılık-seçicilik düzeyinin belirlenmesi, Ege Üniversitesi Hemşirelik Fakültesi Dergisi 2012;28(1):57-71.

31. Zhang C, Wu X, Lin S, Jia Z, Cao J. Evaluation of Reliability and Validity of the Hendrich II Fall Risk Model in a Chinese Hospital Population. PLoS One. 2015;10(11):e0142395.

32. Gözüm S, Aksayan S. Kültürlerarası ölçek uyarlaması için rehber II: Psikometrik özellikler ve kültürlerarası karsılastırma. Hemsirelikte Arastırma Gelistirme Dergisi 2003;5(1):3-14.

33. Nunnally C, Bernstein H, Psychometric Theory. 3th ed. McGraw-Hill; 1994.

34. Hayakawa T, Hashimoto S, Kanda H, Hirano N, Kurihara Y, Kawashima T et al. Risk factors of falls in inpatients and their practical use in identifying high-risk persons at admission: Fukushima Medical University Hospital cohort study. BMJ Open. 2014;4(8):e005385.

35. Akobeng AK. Understanding diagnostic tests 1: sensitivity, specificity and predictive values, Acta Pædiatrica. 2007;96:338-341.

36. Baek S, Piao J, Jin Y, Lee SM. Validity of the Morse Fall Scale implemented in an electronic medical record system. J Clin Nurs. 2014;23(17-18):2434-2440.

37. Watson BJ, Salmoni AW, Zecevic AA. The use of the Morse Fall Scale in an acute care hospital, Clin Nurs Stud. 2016;4(2):32-40.

38. Klinkenberg WD, Potter P. Validity of the Johns Hopkins Fall Risk Assessment Tool for predicting falls on inpatient medicine services. J Nurs Care Qual. 2017;32(2):108-113.

39. Hajian-Tilaki K. Receiver operating characteristic (ROC) curve analysis for medical diagnostic test evaluation. Caspian J Intern Med. 2013;4(2):627-635.

40. Soydemir D, Seren Intepeler S, Mert H. Barriers to medical error reporting for physicians and nurses. Western Journal of Nursing Research 2017;39(10):1348-1363.

41. Hill A, Hoffmann T, Hill KD, Oliver D, Beer C, Mcphail S et al. Measuring falls events in acute hospitals-a comparison of three reporting methods to identify missing data in the hospital reporting system. Journal of the American Geriatrics Society 2010;58(7):1347-1352.

42. Shorr RI, Mion LC, Chandler AM, Rosenblatt LC, Lynch D, Kessler LA. Improving the capture of fall events in hospitals: combining a service for evaluating inpatient falls with an incident report system. Journal of the American Geriatrics Society 2008;56(4):701-704. 